\title{
Study on Seismicity and Secondary Disaster Countermeasures of Offshore Earthquake of China
}

\author{
Changlong Li \\ Institute of Geophysics, China Earthquake Administration \\ Beijing, China \\ changlongli@163.com

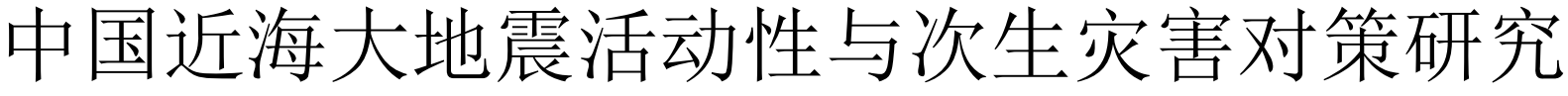 \\ 李昌珑 \\ 中国地震局地球物理研究所 \\ 北京 100081, 中国 \\ changlongli@163.com
}

\begin{abstract}
According to statistics, there have been about 420 earthquakes with M6 or higher in China's coastal and offshore areas since the record, including 63 earthquakes with $M 7$ or higher and 3 earthquakes of M8 and above, showing high major earthquake seismicity. At the same time, due to the economic growth of China in recent years, the population, infrastructure and major projects in the coastal areas have increased rapidly. Therefore, it is of great significance to study the dangers of large earthquakes in China's offshore and disaster risk countermeasures. In this paper, we use the data of the fifth generation of China Seismic Hazard Map to calculate the frequency of earthquakes in the offshore areas of China and the offshore areas above the Bohai Sea, the Yellow Sea, the East China Sea and the South China Sea, and give the major disaster risk countermeasures in the coastal and offshore areas. This paper shows that the frequency of earthquakes larger than M6 in the offshore areas of the Bohai Sea, the Yellow Sea, the East China Sea, the South China Sea and the whole region is about $0.036,0.054,1.03,0.28$ and 1.4 times per year respectively, and the frequency of earthquakes above $M 7$ is about $0.014,0.021,0.46,0.14$ and 0.68 time per year respectively. The potential risks of land liquefaction must be guarded in the coastal and estuary delta areas. The potential risks of offshore wave storm, tsunami and land sinking must be guarded in the coastal areas of Fujian, Taiwan, Guangdong and northern Hainan.
\end{abstract}

Key words: major earthquake, offshore, seismic risk, land liquefaction, tsunami

摘要根据统计资料, 有记录以来中国沿海和近海地 区共发生 6 级以上地震约 420 次, 其中 7 级以上地震 63 次, 8 级以上地震 3 次, 大地震活动频繁。同时, 由于 中国近年经济的增长, 沿海地区的人口、基础设施、重 大工程迅速增加。因此, 研究中国近海大地震危险性与 灾害风险对策具有重要的意义。本文使用第五代《中国 地震动参数区划图》的资料，计算了中国近海全域及渤 海、黄海、东海、南海各海域近海 6 级以上地震的活动 频率, 并对沿海和近海地区面临的主要灾害及其风险给 出了对策建议。本文研究表明, 渤海、黄海、东海、南 海近海海域及全域 6 级以上地震的发生频次分别约为 $0.036 、 0.054 、 1.03 、 0.28 、 1.4$ 次/年，7 级以上地震的 发生频次分别约为 $0.014 、 0.021 、 0.46 、 0.14 、 0.68$ 次/ 年。在沿海滩涂、河口三角洲地区须防范土地液化的潜
在风险。在福建、台湾、广东和海南北部沿海须防范近 海浪涌、海啸、陆地沉陷的潜在风险。

关键词: 大地震; 近海; 地震风险; 土地液化; 海啸

\section{I. 引言}

我国拥有大陆海岸线 1.8 万千米和海域领土 300 万 平方千米，是海洋大国。同时，我国沿海和近海海域地 震活动频繁。根据统计资料, 有记录以来中国沿海和近 海地区共发生 6 级以上地震约 420 次, 其中 7 级以上地 震 63 次, 8 级以上地震 3 次, 大地震次数多, 强度强。 由于中国近年经济的增长，沿海地区的人口、基础设 施、重大工程迅速增加。因此, 研究中国近海大地震危 险性与灾害风险对策具有重要的意义。近年来陆域和海 域的地震危险性研究已在世界范围内广泛开展 ${ }^{[1]}$ 。本文 使用第五代《中国地震动参数区划图》（GB 183062015） ${ }^{[2]}$ 的资料，计算了中国近海全域及渤海、黄海、 东海、南海各海域近海 6 级以上地震的活动频率，并对 沿海和近海地区面临的主要灾害及其风险给出了对策建 议。

II. 中国近海大地震潜在震源区分布和强震发生率研 究

\section{A. 渤海大地震潜在震源区分布和强震发生率研究}

根据五代图的潜源划分，渤海海域分属华北平原地 震带和郯庐地震带 ${ }^{[3]}$ 。渤海海域潜在震源区划分如图 1 所示。在渤海海域内共有震级上限大于 6 级的潜在震源 区 20 个。历史上共记录到 $M \geqslant 6$ 地震 15 次（图 1)。 根据五代图各潜源的地震活动性参数计算得到, 渤海海 域 6 级以上地震的年发生率为 0.036 , 即未来 10 年发生 至少 1 次 6 级以上地震的概率为 $38 \%$ 。7 级以上地震的 年发生率为 0.014 , 即未来 10 年至少发生 1 次 7 级以上 地震的概率为 $15 \%$ 。 


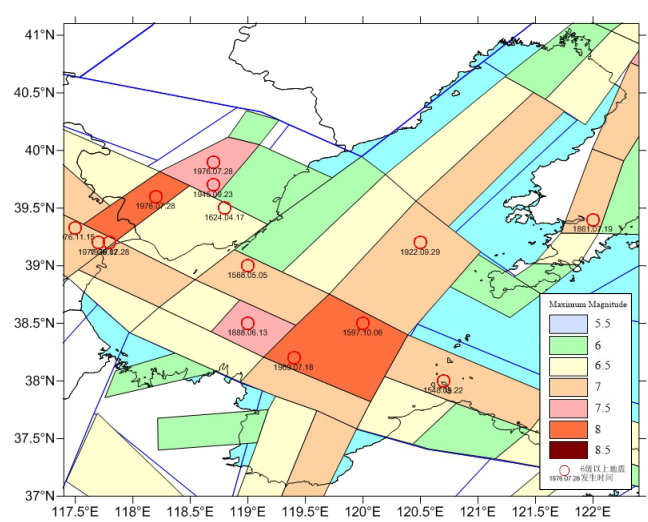

图 1 渤海海域潜在震源区划分及历史上 $\mathrm{M} \geqslant 6$ 地震分布图

\section{B. 黄海大地震潜在震源区分布和强震发生率研究}

黄海潜在震源区划分如图 2 所示。黄海近海共有震 级上限大于 6 级的潜在震源区 18 个。历史上共记录到 $M \geqslant 6$ 地震 18 次（图 2)。根据五代图各潜源的地震活 动性参数计算得到, 黄海海域 6 级以上地震的年发生率 为 0.054 , 即未来 10 年发生至少 1 次 6 级以上地震的概 率为 $56 \%$ 。7 级以上地震的年发生率为 0.021 , 即未来 10 年至少发生 1 次 7 级以上地震的概率为 $23 \%$ 。

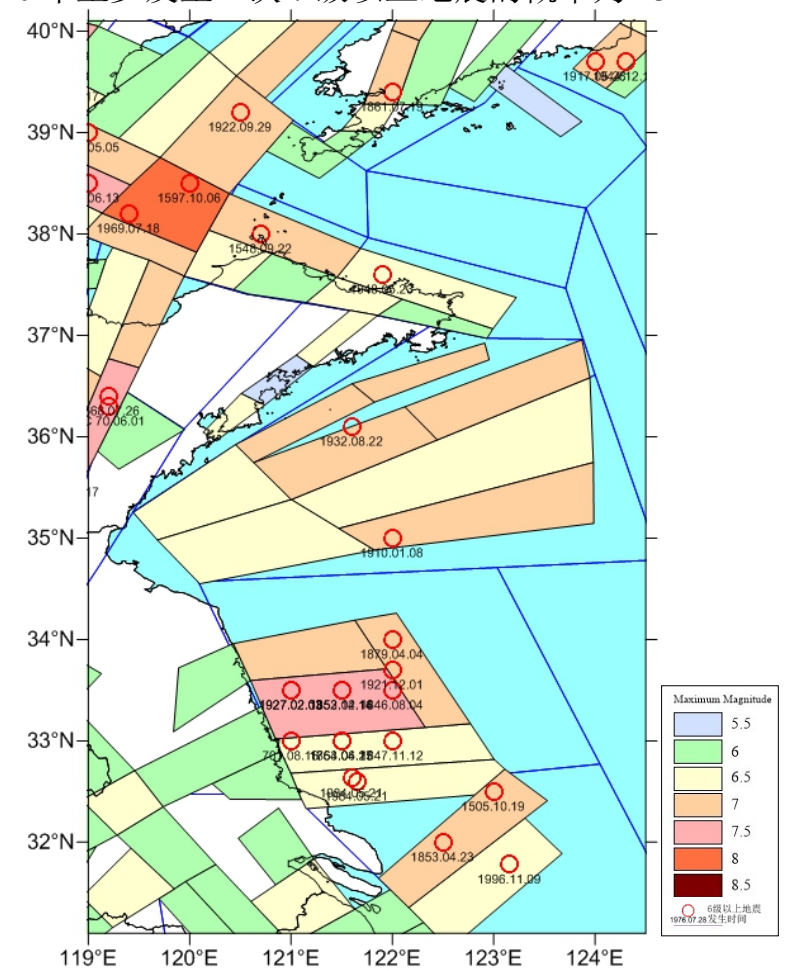

图 2 黄海海域潜在震源区划分及历史上 $M \geqslant 6$ 地震分布图

\section{C. 东海大地震潜在震源区分布和强震发生率研究}

东海潜在震源区划分如图 3 所示。东海近海共有震 级上限大于 6 级的潜在震源区 29 个。历史上共记录到 $\mathrm{M} \geqslant 6$ 地震 388 次 (图 3)。根据五代图各潜源的地震活 动性参数计算得到, 东海海域 6 级以上地震的发生频次 为 1.03 次/年, 7 级以上地震的发生频次为 0.46 次/年。

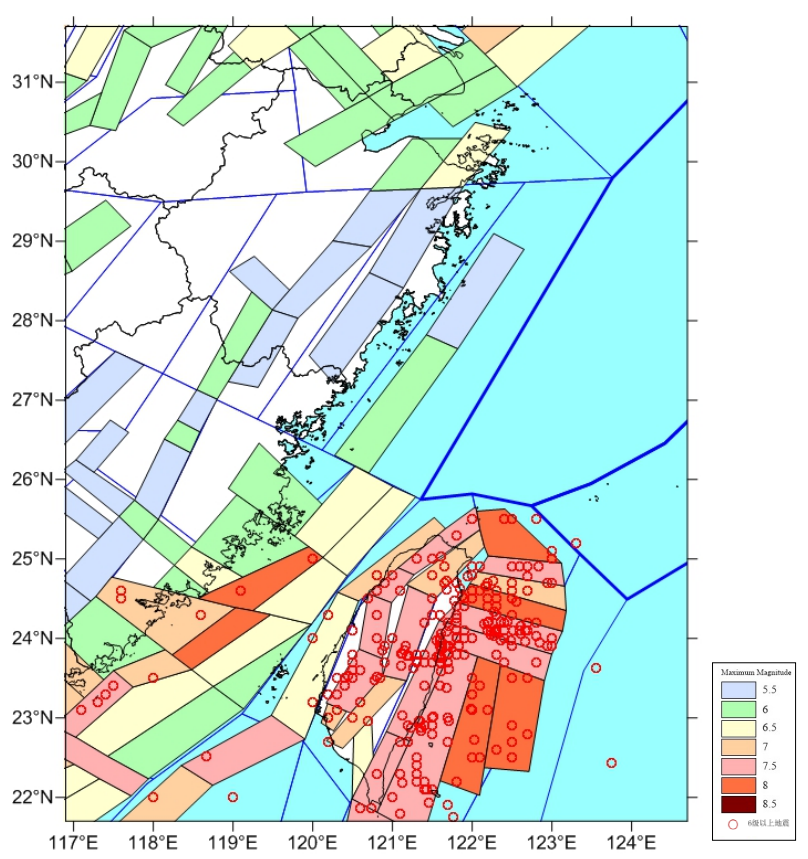

图 3 东海海域潜在震源区划分及历史上 $M \geqslant 6$ 地震分布图

$D$. 南海大地震潜在震源区分布和强震发生率研究

南海潜在震源区划分如图 4 所示。南海近海共有震 级上限大于 6 级的潜在震源区 30 个。历史上共发生 M $\geqslant 6$ 地震 15 次 (图 4)。根据五代图各潜源的地震活动 性参数计算得到, 南海海域 6 级以上地震的发生频次为 0.28 次/年, 7 级以上地震的发生频次为 0.14 次/年。

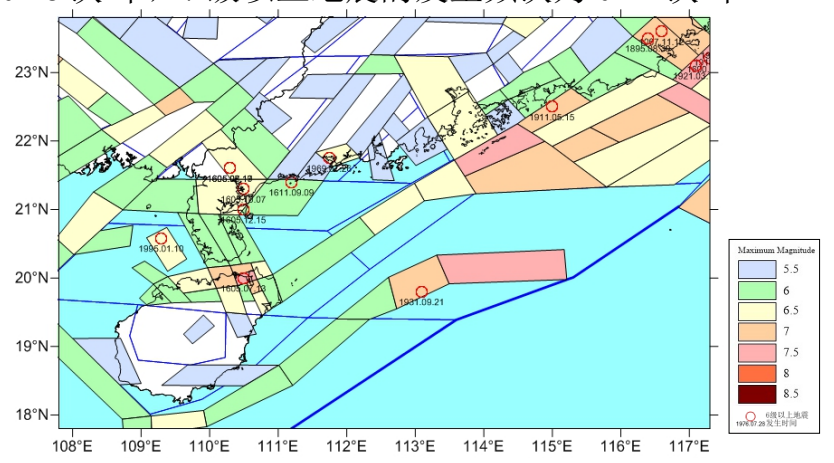

图 4 南海海域潜在震源区划分及历史上 $M \geqslant 6$ 地震分布图

综上, 我国近海海域共有震级上限大于 6 级的 潜在震源区 97 个。历史上记录到 $M \geqslant 6$ 地震 420 次。全 域 6 级以上和 7 级以上地震的发生频次分别为 1.4 次/年 和 0.68 次/年。

\section{III. 中国近海大地震诱发灾害及风险对策建议}

土地液化是沿海大地震中容易发生的次生灾害现 象, 比较著名的如 2018 年印度尼西亚帕卢地震引起的 土地液化 ${ }^{[4]}$ 。中国大陆海岸大致以长江口为界, 以北以 泥沙质海岸为主, 以南以基岩质海岸为主。在泥沙质海 岸和河口三角洲地区, 土质松软, 含水量很高, 一旦发 生近海大地震, 很容易发生土地液化现象, 需特别防 范。

我国沿海也有发生地震引起的浪涌、海啸和地面沉 陷灾害的潜在风险。根据王锋等 (2005) ${ }^{[5]}$ 的研究, 历 史上我国共记载过地震诱发近海浪涌、海啸和地面沉陷 灾害 9 起, 如表 1 所示。9 起灾害对应的历史地震发生 
地点及时间如图 5 所示。可见, 我国整个近海海域都发 生过确切可考的地震诱发近海浪涌、海啸和陆地沉陷灾 害, 特别在福建、广东、台湾近海, 未来的城市规划、 工程设施选址及设防需特别考虑近海大地震及其诱发次 生灾害的风险。

表 1 我国历史上记载的地震诱发近海浪涌、海啸和地面沉陷灾 害概况表, 根据王锋等 (2005) ${ }^{[5]}$ 的研究整理

\begin{tabular}{|c|c|c|c|c|c|c|c|}
\hline $\begin{array}{l}\text { 序 } \\
\text { 号 }\end{array}$ & 时间 & $\begin{array}{l}\text { 震 } \\
\text { 级 }\end{array}$ & 震中 & $\begin{array}{c}\text { 影响范 } \\
\text { 围 }\end{array}$ & 损失 & $\begin{array}{l}\text { 灾害 } \\
\text { 类型 }\end{array}$ & $\begin{array}{c}\begin{array}{c}\text { 最大波高 } \\
(\mathbf{m})\end{array} \\
\end{array}$ \\
\hline 1 & $\begin{array}{c}1604 \\
.12 .2 \\
9\end{array}$ & 7.5 & $\begin{array}{l}\text { 福建 } \\
\text { 泉州 } \\
\text { 近海 }\end{array}$ & 泉州 & 覆舟甚多 & 海啸 & $2-3$ \\
\hline 2 & $\begin{array}{c}1605 \\
.07 .1 \\
3\end{array}$ & 7.5 & $\begin{array}{l}\text { 海南 } \\
\text { 海口- } \\
\text { 文昌 }\end{array}$ & $\begin{array}{c}\text { 海南北 } \\
\text { 部 }\end{array}$ & $\begin{array}{l}\text { 琼山调塘、 } \\
\text { 演顺等都 } \\
\text { (东寨港内) } \\
\text { 沉陷数十村 }\end{array}$ & $\begin{array}{l}\text { 陆地 } \\
\text { 沉陷 }\end{array}$ & I \\
\hline 3 & $\begin{array}{c}1668 \\
.07 .2 \\
5\end{array}$ & 8.5 & $\begin{array}{l}\text { 山东 } \\
\text { 郯城 }\end{array}$ & $\begin{array}{l}\text { 黄海沿 } \\
\text { 海, 远 } \\
\text { 至江 } \\
\text { 南、朝 } \\
\text { 鲜 } \\
\end{array}$ & $\begin{array}{c}\text { 赣榆海退, } \\
\text { 河水暴涨, } \\
\text { 海潮大益 }\end{array}$ & 浪涌 & 3 \\
\hline 4 & $\begin{array}{c}1792 \\
.08 .0 \\
9 \\
\end{array}$ & 7 & $\begin{array}{l}\text { 台湾 } \\
\text { 嘉义 }\end{array}$ & $\begin{array}{l}\text { 嘉义、 } \\
\text { 台南 }\end{array}$ & $\begin{array}{c}\text { 鹿耳门忽无 } \\
\text { 风水涌起数 } \\
\text { 丈 }\end{array}$ & 浪涌 & 3 \\
\hline 5 & $\begin{array}{c}1867 \\
.12 .1 \\
8\end{array}$ & 7 & $\begin{array}{l}\text { 台湾 } \\
\text { 基隆 }\end{array}$ & $\begin{array}{l}\text { 基隆、 } \\
\text { 宜、 } \\
\text { 花莲 }\end{array}$ & $\begin{array}{l}\text { 基隆全市倒 } \\
\text { 坏, 地衣涌 } \\
\text { 水, 水石滚 } \\
\text { 落, 鸡笼山 } \\
\text { 崩缺, 淡水 } \\
\text { 死 } 30 \text { 余 } \\
\text { 人, 台北死 } \\
150 \text { 余人。 }\end{array}$ & $\begin{array}{l}\text { 浪涌 } \\
\text { 海啸 }\end{array}$ & 7.5 \\
\hline 6 & $\begin{array}{c}1917 \\
.07 .0 \\
4 \\
\end{array}$ & 7 & $\begin{array}{l}\text { 台湾 } \\
\text { 宜兰 } \\
\text { 外海 }\end{array}$ & $\begin{array}{l}\text { 基隆、 } \\
\text { 宜兰 }\end{array}$ & 不详 & 海啸 & 3.7 \\
\hline 7 & $\begin{array}{c}1918 \\
.02 .1 \\
3 \\
\end{array}$ & 7.3 & $\begin{array}{l}\text { 广东 } \\
\text { 南澳 } \\
\text { 近海 }\end{array}$ & $\begin{array}{c}\text { 粤东闽 } \\
\text { 南 }\end{array}$ & 鱼船多遭没 & 海啸 & $2-3$ \\
\hline 8 & $\begin{array}{c}1948 \\
.05 .2 \\
3\end{array}$ & 6 & $\begin{array}{l}\text { 山东 } \\
\text { 威海 }\end{array}$ & 威海 & $\begin{array}{c}\text { 海水冲入陆 } \\
\text { 地里许 }\end{array}$ & 浪涌 & $2-3$ \\
\hline 9 & $\begin{array}{c}1986 \\
.11 .1 \\
5\end{array}$ & 7.3 & $\begin{array}{l}\text { 台湾 } \\
\text { 花莲 } \\
\text { 外海 }\end{array}$ & $\begin{array}{l}\text { 花莲、 } \\
\text { 宜兰 }\end{array}$ & $\begin{array}{c}\text { 花莲、宜兰 } \\
\text { 两处港内 } \\
10 \text { 艘渔船 } \\
\text { 沉没, } 6 \text { 人 } \\
\text { 受伤 }\end{array}$ & 海啸 & 3 \\
\hline
\end{tabular}

\section{IV. 结论和讨论}

本文使用第五代《中国地震动参数区划图》

（GB 18306-2015）的资料, 计算了中国近海全域及渤 海、黄海、东海、南海各海域近海 6 级以上地震的活动 频率, 整理了中国历史上近海大地震及次生灾害资料, 得出了以下结论:

(1) 渤海、黄海、东海、南海近海海域及全域 6 级 以上地震的发生频次分别约为 $0.036 、 0.054 、 1.03$ 、 $0.28 、 1.4$ 次/年, 7 级以上地震的发生频次分别约为 $0.014 、 0.021 、 0.46 、 0.14 、 0.68$ 次/年。

(2) 在沿海滩涂、河口三角洲地区须防范土地液化 的潜在风险。在福建、台湾、广东和海南北部沿海须防 范近海浪涌、海啸、陆地沉陷的潜在风险。

本文的海啸仅考虑了近海地震引起的海啸。有研究 表明, 我国海啸的最大威胁来自远海, 如马尼拉海沟和
日本海沟 ${ }^{[6]}$ 。历史上也多次记录到日本南海大地震海啸 影响我国华东沿海 ${ }^{[5]}$ 。这些在本文中未考虑。

我国在应对地震灾害方面有悠久的历史和丰富的经 验, 也已有抗震设防的国家强制性标准, 但在应对近海 地震次生灾害如土地液化、浪涌海啸、陆地沉陷方面并 无太多经验。今后应在近海地震次生灾害防御方面增加 研究, 增强应对各类自然灾害风险能力。

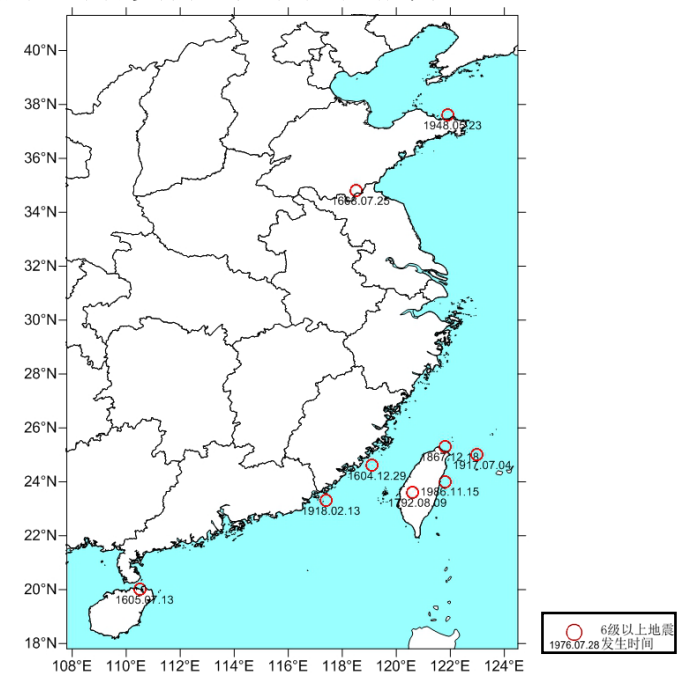

图 5 历史上引起近海浪涌、海啸、地面沉陷灾害的地震及发生 时间

\section{V. 致谢}

本文的中国近海潜在震源区划分来自《中国地震动 参数区划图（GB 18306-2015）》 [2]。历史地震资料来自 《中国地震目录》[7]。本文由国家重点研发计划 (2017YFC1500405) 和中国地震局地球物理研究所基 本科研业务费专项（DQJB17T04）联合资助。

$$
\text { 参考文献 }
$$

[1] Li C L, Gao M T. 2019. Seismic Hazard Model Harmonization in Tienshan Area. Journal of Risk Analysis and Crisis Response, 9(2): 74-84.

[2]中华人民共和国国家质量监督检验检疫总局, 中国国家标 准化管理委员会. 2015. 中国地震动参数区划图. GB 183062015.

[3]周本刚, 陈国星, 高战武, 等. 2013. 新地震区划图潜在震 源区划分的主要技术特色. 震灾防御技术, 8(2): 113-124.

[4]新华网. 2018. 印尼地震海啸过导致 “土壤液化” 灾区清理 重建工作难度大. http://www.xinhuanet.com/video/201810/11/c 129969367.htm.

[5]王锋, 刘昌森, 章振铨. 2005. 中国古籍中的地震海啸记录. 中国地震, 21(3): 437-443.

[6]陈颙, 陈棋福, 张尉. 2007. 中国的海啸灾害. 自然灾害学 报, 16(2): 1-6.

[7]顾功叙, 林庭煌, 时振梁, 等. 1983. 中国地震目录: 公元前 1831-公元 1969 年. 北京: 科学出版社. 